\title{
'Heaping Offa upon Pelion, and Olympus upon Offa': An assessment of the role of model making in the development of relief portrayal from 1780 to 1900.
}

\author{
Alastair William Pearson ${ }^{\mathrm{a}, *}$ \\ ${ }^{a}$ University of Portsmouth, alastair.pearson@port.ac.uk \\ * Corresponding author
}

Keywords: History of cartography, relief portrayal, model making, relief models

\begin{abstract}
:
By 1800, national surveys had become a priority for regimes around Europe, keen to centralise government and secure territories during a period of significant political upheaval. Military requirements were paramount but the representation of relief remained woefully inadequate. Commanders, not content with simple rough impressions of relief, demanded effective representations from which absolute altitudes and gradients could be derived. However, innovative methods of relief depiction were unlikely to be spearheaded by new national mapping institutions, already committed to long-term mapping programmes. Conversely, for those independent cartographers and model makers, unfettered by the constraints that characterised national institutions, the pursuit of the optimum depiction of relief became a preoccupation verging on obsession. Inspired by early map and model makers, Swiss, German and Austrian cartographers embarked on a phase of developing more artistic, naturalistic means to create an illusion of the third dimension on the two-dimensional face of the map. Chromolithography had made possible the replacement of hachures by shading tones and the production of multicolour printed maps. As a result, a wide variety of maps appeared during the second half of the 19th century with hypsometric tints generating images of naturalistic and symbolic landscapes. Alternative and often competing methods of assigning colour in sequence were developed most notably in central Europe. This culminated in the publication of Schatthenplastik and Farbenplastik in 1898 in Vienna by Karl Peucker (1859-1940) a work that injected new life and debate into the pursuit of an optimum colour sequence for layered relief maps that would last well into the next century.

This paper aims to assess the role of model making in initiating and fuelling a period of experimentation and development of relief portrayal. The increasing fascination with the natural wonders of the world combined with the growth of Alpine tourism kick started a period of private enterprise in which the production of relief models became a highly valued activity. Starting with the remarkable model of the Relief of Central Switzerland by Franz Ludwig Pfyffer von Wyher (1716-1802), through the exploits of Joachim Eugen Müller (1752-1833) (Figure 1) to the later models crafted by Xaver Imfeld (1853-1909), Simon Simon (1857-1925) and Fridolin Becker (1854-1922), this period witnessed a level of artistry and craftsmanship that has arguably never been surpassed.
\end{abstract}

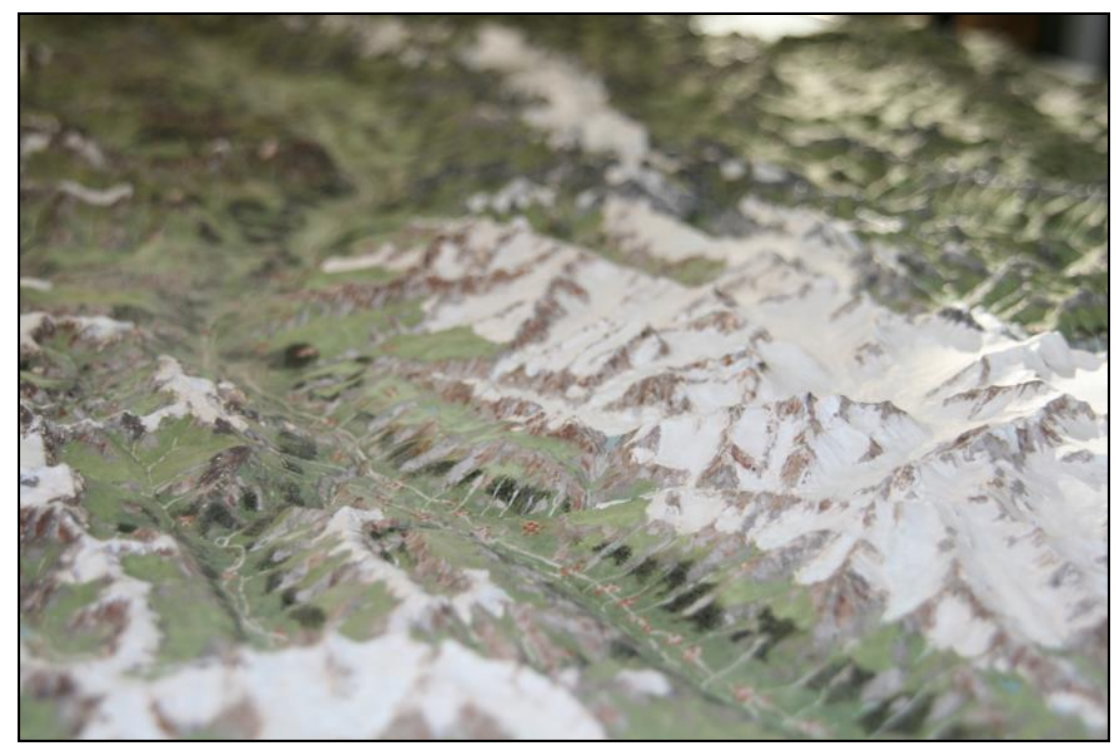

Figure 1. Relief of a part of the Bernese Oberland and the Valais 1:60,000, 74 x $109 \mathrm{~cm}$, Joachim Eugen Müller, around 1800 , provided a basis for the creation of the "Atlas Suisse par Meyer et Weiss". 
Opportunity is taken to assess the accuracy of one of the key models produced by Joachim Eugen Müller. This clearly demonstrates that early model making achieved standards of accuracy that were extraordinary for the time. Of course, such feats were not the preserve of European model makers. For example, readers of reports and newspaper articles from expeditions to the interior of the United States had thrilled at the photographs, drawings, sketches and maps of Niagara Falls, Yosemite Valley and the Grand Canyon. No sooner had John Wesley Powell completed his expedition to the Grand Canyon in 1874 and published a detailed report, than its true magnificence was brought to public attention through a model of the Grand Canyon constructed by Edwin Howell in 1875 (McCalmont, 2015).

The nineteenth century was characterized by great endeavour and craftsmanship that fashioned some of the most remarkable and visually stunning maps ever published. This paper pulls together the various strands of this complex story into a coherent narrative and assesses the role of model makers in underpinning this 'golden age'. 